\title{
DEVELOPMENT OF LOW THERMAL EXPANSION SUPERALLOYS
}

\author{
Koji Sato and Takehiro Ohno \\ Metallurgical Research Laboratory, Yasugi Works \\ Hitachi Metals, Ltd. \\ 2107-2 Yasugi, Shimane, 692, JAPAN
}

\begin{abstract}
Alloy 903 and alloy 909 are famous $\mathrm{Fe}-\mathrm{Co}-\mathrm{Ni}-\mathrm{Al}-\mathrm{Ti}-\mathrm{Nb}$ alloys with controlled low thermal expansion, but they have certain properties which can be improved. To improve stress accelerated grain boundary oxidation embrittlement (SAGBO) of a $170 y 903$ and instability of the gamma prime phase of alloy 909 , two new alloys with good stress rupture ductility, high creep rupture strength, high tensile strength at high temperature, and good controlled thermal expansion were developed. These property improvements were accomplished by the combination of optimizing the $\mathrm{Fe}-\mathrm{Co}-\mathrm{Ni}$ ratio of the matrix and stabilizing the gamma prime phase with the addition of Al.
\end{abstract}




\section{Introduction}

For heat resistant gas turbine components, superalloys with controlled low thermal expansion coefficients can solve the high temperature problems of thermal stress and clearance. Alloy 903 is one of the famous Fe-Co-Ni-Al$\mathrm{Ti}-\mathrm{Nb}$ alloys with controlled low thermal expansion, but the alloy is susceptible to stress accelerated grain boundary oxidation embritllement (SAGBO) above about $500 \mathrm{C}(1,2)$. This phenomenon is related to notch bar stress rupture embrittlement in air around 500C. Alloy 909, which solved the SAGBO problem of alloy 903, was developed by the elimination of $A 1$, the addition of $\mathrm{Si}$ and strengthening by $\mathrm{Nb}$ and $\mathrm{Ti}(3)$. The improvement in strength for alloy 909 is directly related to the presence of a $\mathrm{Ni}-\mathrm{Nb}$ rich Laves phase. It precipitates during hot working and solution treatment, refines the grain size and modifies the grain boundary structure $(4,5)$. However, the lack of $\mathrm{Al}$ and excessive amount of $\mathrm{Nb}$ in alloy 909 have sacrificed the advantage of alloy 903, namely a more stable gamma prime phase at high temperature. If strain is introduced to the matrix of alloy 909 between the annealing and aging treatments, this instability of the gamma prime phase causes the precipitation of $\varepsilon^{\prime \prime}$ phase, ( $\left.\mathrm{Ni}, \mathrm{Co}, \mathrm{Fe}\right) 3(\mathrm{Ti}, \mathrm{Nb})$, which decreases tensile strength (6).

Considering the above characteristics of low thermal expansion superalloys, we tried to develop new alloys which would have a stable gamma prime phase like alloy 903, and a dispersion of small $\mathrm{Ni}-\mathrm{Nb}$ rich Laves precipitates like alloy 909 to refine the grain size. Furthermore, we made an effort to provide superalloys with a lower coefficent of thermal expansion and higher elevated temperature tensile strength than alloy 903 and alloy 909. For heat resistant alloys it is useful to decrease the thermal expansion for improved adherance of low thermal expansion ceramic coatings like silicon nitride, and it is also advantageous to increase tensile strength for prolonged 1 ife.

\section{Experimental Procedure}

The experimental alloys and conventional alloys were melted in a vacuum induction furnace and cast into $10 \mathrm{~kg}$ ingots. Table 1 shows chemical compositions of these alloys. Heats $6-1$ and $6-2$ are the same alloy. Heat 6-1

\begin{tabular}{|c|c|c|c|c|c|c|c|c|}
\hline Heat & $\mathrm{C}$ & $\mathrm{Si}$ & $\mathrm{Ni} \quad \mathrm{Co}$ & $\mathrm{Cr}$ & $\mathrm{Al} \quad \mathrm{Ti}$ & $\mathrm{Nb}$ & $\mathrm{Fe}$ & B \\
\hline 1 & 0.03 & $<0.01$ & 26.323 .2 & & $<0.011 .56$ & 4.72 & $\mathrm{Bal}$ & 0.004 \\
\hline 2 & 0.03 & 0.02 & $29.4 \quad 19.6$ & & $<0.01 \quad 1.56$ & 4.74 & $\mathrm{Ba}$ & 0.005 \\
\hline 3 & 0.03 & 0.45 & $26.4 \quad 23.2$ & & $<0.01 \quad 1.53$ & 4.71 & Bal & 0.004 \\
\hline 4 & 0.03 & 0.49 & 29.319 .6 & & $<0.01 \quad 1.64$ & 4.74 & $\mathrm{Bal}$ & 0.005 \\
\hline & 0.03 & 0.44 & $26.5 \quad 23.2$ & & 0.571 .30 & 4.08 & $\mathrm{Ba}$ & 0.005 \\
\hline 6-1\} developed & 0.03 & 0.45 & 29.219 .6 & & 0.55 & 4.02 & $\mathrm{Ba}$ & 0.004 \\
\hline $6-2 J$ alloy $A$ & 0.03 & 0.44 & $29.3 \quad 19.6$ & & 0.50 & & & \\
\hline 7-1 t developed & 0.04 & 0.31 & 29.522 .5 & 2.03 & 0.54 & 4.07 & $\mathrm{Ba}$ & 0.004 \\
\hline $7-2\}$ alloy B & 0.03 & 0.33 & $29.4 \quad 22.8$ & 1.99 & 0.53 & 4.17 & $\mathrm{Ba}$ & 0.005 \\
\hline$\frac{8}{0}$ & 0.04 & 0.31 & $33.4 \quad 18.2$ & 1.51 & $0.55 \quad 1.29$ & 4.07 & $\mathrm{Ba}$ & 0.004 \\
\hline alloy903 & 0.03 & $<0.01$ & $\begin{array}{lll}37.8 & 15.0\end{array}$ & 0.16 & 0.811 .47 & 2.69 & & 0.006 \\
\hline a $110 y 909$ & $\leq 0.0$ & 0.43 & $38.2 \quad 13.2$ & 0.03 & $0.06 \quad 1.42$ & 4.71 & $\mathrm{Ba}$ & 0.007 \\
\hline
\end{tabular}

was used for basic experiments and heat 6-2 was used for evaluation tests. The relationship between heat $7-1$ and $7-2$ is the same as the relationship between heat 6-1 and 6-2. Heats 9 and 10 are a $710 y 903$ and alloy 909, respectively. They were melted according to the compositions shown in Ref. 6.

Al1 alloys except alloy 903 were homogenized at $1150 \mathrm{C}$ for $20 \mathrm{hr}$ and forged into 30-mm-square bars. Specimens were heat treated as noted in Table 2 . 
Table 2 Heat-treating schedule

\begin{tabular}{l|lll}
\hline Solution & $982 \mathrm{~W} / 1 \mathrm{H}, \mathrm{AC}$ & $\cdots$ for all alloys except Alloy903 \\
treatment & $930 \mathrm{\textrm {C }} / 1 \mathrm{H}, \mathrm{AC}$ & $\cdots$ & for on $\mathrm{On}$ Alloy903 \\
\hline Aging & Standard & $\cdots$ & $720 \mathrm{~W} / 8 \mathrm{H} \rightarrow 55 \mathrm{~W} / \mathrm{H} \rightarrow 620 \mathrm{\textrm {H }} / 8 \mathrm{H}, \mathrm{AC}$ \\
treatment & 0veraging & $\cdots$ & $750 \mathrm{\textrm {C }} / 1.5 \mathrm{H} \rightarrow 850 \mathrm{\textrm {H }} / 0.5 \mathrm{H} \rightarrow 100 \mathrm{\textrm {H }} / \mathrm{H} \rightarrow 650 \mathrm{~T}, \mathrm{AC}$ \\
\hline
\end{tabular}

Alloy 903 was solution treated at $930 \mathrm{C}$ to retain a fine grain size because it does not have Laves phase. Aging treatments were conducted at standard conditions. Overaging treatments, which simulated real brazing treatments, were carried out to examine the stability of the gamma prime.

Microstructures of these specimens were observed by optical microscopy and transmission electron microscopy (TEM). Tensile tests and creep rupture tests were conducted in air using ASTM testing methods. Specimens were oriented in the longitudinal direction. A specimen with a $6.35 \mathrm{~mm}$ diameter was used for tensile testing. A combination smooth/notched specimen with gage and notch diameters of $4.52 \mathrm{~mm}$ was used for creep rupture testing. The coefficients of thermal expansion (CTE) were determined from $30 \mathrm{C}$ up to $800 \mathrm{C}$ by differential thermal expansion testing methods. 0xidation tests were carried out by using $7 \mathrm{~mm}$ diameter $\times 15 \mathrm{~mm}$ long specimens. After $100 \mathrm{hr}$ at $800 \mathrm{C}$ in air, the thickness of internal and external oxidation layers was measured using optical microscopy techniques.

\section{Development of A Lower Thermal Expansion Superalloy}

\section{Alloy Design}

Heats 1 to 6 in Table 1 are the experimental alloys for this study. First of all, we tried to raise the Co/Ni ratio above those for alloy 903 and alloy 909 in order to decrease the thermal expansion according to the relationship between Invar (36Ni-Fe) and Super Invar (31Ni-5Co-Fe). In addition, increasing the $\mathrm{Co} / \mathrm{Ni}$ ratio would be expected to increase the amount of Laves phase (helpful in preventing SAGBO embrittlement) because the solubility of $\mathrm{Nb}$ in the $\mathrm{C}_{0}-\mathrm{Nb}$ binary system is lower than that in the $\mathrm{Ni}-\mathrm{Nb}$ binary system. Heats 1,3 , and 5 have about $26.4 \mathrm{wt} \% \mathrm{Ni}$ and $23.2 \mathrm{wt} \%$ $\mathrm{Co}(\mathrm{Co} / \mathrm{Ni}=0.88)$; heats 2,4 and 6 have about $29.3 \mathrm{wt} \% \mathrm{Ni}$ and $19.6 \mathrm{wt} \% \mathrm{Co}_{0}$ $(\mathrm{Co} / \mathrm{Ni}=0.67)$. By comparing these two groups, the effect of the difference in $\mathrm{Co} / \mathrm{Ni}$ ratio was examined. Secondly, additions of $\mathrm{Al}, \mathrm{Ti}$ and $\mathrm{Nb}$ for the $\mathrm{Co} / \mathrm{Ni}$ ratio mentioned above were investigated in order to obtain stable gamma prime precipitates. Heats 1 to 4 have the same amount of $\mathrm{Ti}$ and $\mathrm{Nb}$ as alloy 909. Heats 5 and 6 have the same amount of $A 1$, $\mathrm{Ti}$ and $\mathrm{Nb}$; the $\mathrm{Al}$ is higher and $\mathrm{Ti}$ and $\mathrm{Nb}$ are lower than alloy 909 . The influence of the amounts of $\mathrm{Al}, \mathrm{Ti}$ and $\mathrm{Nb}$ on stability of the gamma prime precipitation hardening

Table 3 Effect of Nickel and Cobalt on coefficient of thermal expansion

\begin{tabular}{|c|c|c|c|}
\hline Heat & $\mathrm{Ni}+\mathrm{Co}_{0}$ & $\mathrm{Co} /\left(\mathrm{Ni}+\mathrm{C}_{0}\right)$ & $\begin{array}{c}\text { CTE: } 30-400 \mathrm{~T} \\
\times 10^{-6} / \tau\end{array}$ \\
\hline 1 & 49.5 & 0.47 & 5.99 \\
\hline 2 & 49.0 & 0.40 & 5.73 \\
\hline 3 & 49.6 & 0.47 & 6.65 \\
\hline 4 & 48.9 & 0.40 & 6.31 \\
\hline & 49.7 & 0.47 & 6.16 \\
\hline $6-1($ alloy $A)$ & 48.8 & 0.40 & 5.79 \\
\hline $9($ a $110 y 903)$ & 52.8 & 0.28 & 7.44 \\
\hline 10 (alloygog) & 51.4 & 0.26 & 7.69 \\
\hline
\end{tabular}
phase and mechanical properties was investigated by comparing heats 1 to 4 with heats 5 to 6 . Thirdly, the effect of $\mathrm{Si}$ on precipitation of Laves phase was investigated by comparing heats 1 and 2 with heats 3 and 4 . 
Table 4 Effect of alloying elements on stress-rupture properties at $500^{\circ} \mathrm{C}$

\begin{tabular}{|c|c|c|c|c|c|c|c|c|c|}
\hline Heat & $\mathrm{Si}$ & AI & $\mathrm{Nb}$ & $\mathrm{Co} /\left(\mathrm{Ni}+\mathrm{C}_{0}\right)$ & Stress & $(\mathrm{MPa}$ & & Elong. & R.A. \\
\hline 1 & $\langle 0,01$ & $<0,01$ & 472 & & $\frac{i n i t i a l}{784}$ & $\frac{\text { fina }}{1078}$ & $\frac{(h)}{318}$ & $(\%)$ & $\frac{(\%)}{27}$ \\
\hline 2 & 0.02 & $<0.01$ & 4.74 & 0.40 & 784 & $\begin{array}{l}1078 \\
1029\end{array}$ & $\begin{array}{l}18.0 \\
290.1\end{array}$ & notch & 27.8 \\
\hline 3 & 0.45 & $<0.01$ & 4.71 & 0.47 & 784 & 1029 & 261.1 & 10.6 & 19.7 \\
\hline 4 & 0.49 & $<0.01$ & 4.74 & 0.40 & 78 & 1078 & 322.8 & 10.3 & 9.9 \\
\hline & 0.44 & 0.57 & 4.08 & 0.47 & 784 & 1029 & 375.4 & 9.5 & 18.1 \\
\hline 6-1 (a1loy A) & 0.45 & 0. & 4.02 & 0.40 & 784 & 1078 & 323.5 & 11.7 & 21.7 \\
\hline
\end{tabular}

a: Specimens were aged by standard aging process

b: After 200h, stress was increased by $49 \mathrm{MPa}$ every 8 to $16 \mathrm{~h}$

\section{Results and Discussion}

Table 3 shows the effects of $\mathrm{Ni}$ and $\mathrm{Co}_{0}$ on the coefficient of thermal expansion (CTE) at temperatures from $30 \mathrm{C}$ to $400 \mathrm{C}$ for the experimental alloys, alloy 903 and alloy 909 , in the standard aged condition. The CTE for heats 1 to 6-1 were lower than those for alloy 903 and alloy 909 by about $1 \times 10-6 / C$. These results are attributed mainly to the increase of the $\mathrm{CO} /(\mathrm{CO}+\mathrm{Ni})$ ratio and partly to the lower amount of $\mathrm{Ni}+\mathrm{CO}_{0}$. The different $\mathrm{Co} /\left(\mathrm{CO}_{\mathrm{O}}+\mathrm{Ni}\right)$ ratios of 0.40 and 0.47 for heats 1 to 6-1 did not significantly affect the CTE.

The effect of alloying elements on stress rupture properties for heats 1 to $6-1$ are shown in Table 4. All

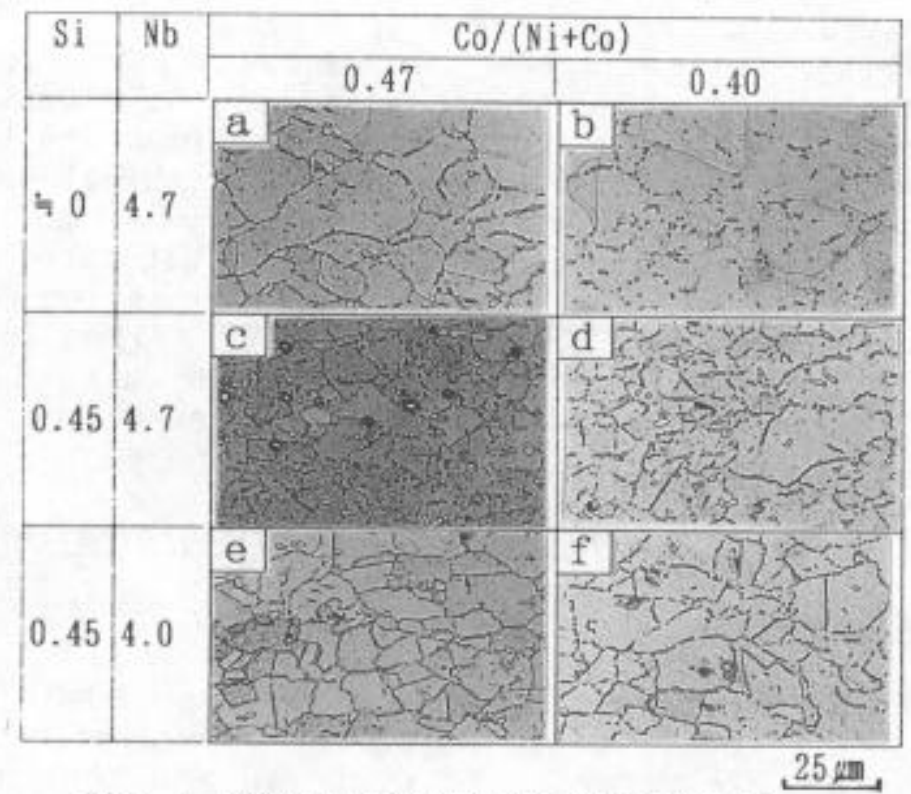

Fig. 1 Effect of alloying elements on aicrostructure of specimens
a: heat 1 ,
b: heat 2,
c: heat 3
d: heat 4 ,
e: heat 5 ,
e: heat 6-1(alloy A) heats except heat 2 had good creep rupture strength and ductility. Only heat 2 failed at the notch location. Fig. 1 shows their microstrutures. The spherical particles of micrometer dimensions, shown at higher magnification in Fig. 4, were identified by TEM diffraction paterns as two and four-layered hexagonal Laves phases, the same phase which forms in alloy 909 (4). By comparing heat 1 with 2 , heat 3 with 4 and heat 5 with 6 , the higher the $\mathrm{Co} /(\mathrm{Co}+\mathrm{Ni})$ ratio, the more the Laves phase was precipitated. Heat 2, having lower silicon and a lower $\mathrm{Co} /(\mathrm{CO}+\mathrm{Ni})$ ratio, precipitated the least amount of Laves phase and had the largest grain size among the experimental heats. Therefore, it was found that the addition of $S i$ and increasing the $\mathrm{Co} /(\mathrm{CO}+\mathrm{Ni})$ ratio increased the amount of Laves phase precipitated, and the Laves phase was beneficial for creep rupture ductility and obtaining a fine grain size. The high affinity of aluminum for oxygen was considered detrimental to rupture ductility and SAGBO embrittlement (7), but $A l$ additions in the cases of heats 5 and 6 did not affect the rupture ductility. From these results, it appears that notch ductility is improved mainly by the existence of

Table 5 Vickers hardness of overaged specimens

\begin{tabular}{c|c|c|c|c}
\hline Heat & 4 & $6-1$ & 9 & 10 \\
\hline Hardness, HV & 319 & alloy A & alloy903 & alloy909 \\
\hline
\end{tabular}


Laves phase and a fine grain size, and the affinity of aluminum for oxygen has little influence on rupture ductility if Laves phase is present.

Comparing the $\mathrm{Co} /(\mathrm{Co}+\mathrm{Ni})$ ratio of 0.40 with 0.47 with Si held constant at $0.45 \%$, there was little difference in rupture ductility and thermal expansion. The reason may be that increasing $\mathrm{C}_{0}$ produces only an increase in the amount of Laves phase, and does not change the matrix composition. Because $C_{0}$ is an expensive element and its production has been unreliable in the past, the high temperature gamma prime stability experiments were conducted only on heats 4 and 6 (lower cobalt heats).

Stability of the gamma prime phase at high temperature was studied by overaging heat 4 , heat 6 , alloy 903 and alloy 909 . Vickers hardness values and microstructures are shown in Table 5 and Fig. 2, respectively. A needle, or platelet, shaped phase was observed in heat 4 and alloy 909 . These two heats had hardness values which were lower than those of heat 6-1 and alloy 903 . The phase is supposed to be the $\varepsilon$ phase, which has a D019 hexagonal Ni3Sn-type structure and is optically similar to the $\delta$ phase in alloy 718 (4). The $\varepsilon$ phase seems to reduce the amount of gamma prime phase and results in lower hardness values. On the other hand, no strange phases except Laves phase were observed in heat 6-1 and alloy 903, and they had higher hardness values than heat 4 and alloy 909 . The reason may be due to the existence of Al which stabilizes the gamma prime phase at high temperature.

As a result of these experiments, it was found that heat 6 was an alloy with a lower coefficient of thermal expansion than alloy 903 and alloy 909 . Heat 6 also had good rupture properties and good gamma prime stability at high temperature. Heat 6 was designated alloy A, and additional evaluation tests were conducted (see expanded mechanical properties evaluation section).

\section{Development of A Higher Strength Low Expansion Superalloy}

\section{Alloy Design}

Alloy A has some margin in thermal expansion when compared to alloy 903 and alloy 909. The addition of $\mathrm{Cr}$ is known to result in a marked incrcase in thermal expansion for alloy 903 (7), but it is supposed to improve high temperature tensile strength by solid solution strengthening the gamma matrix. Furthermore, it increases high temperature oxidation resistance. Therefore, $\mathrm{Cr}$ was added to alloy $\mathrm{A}$ to obtain high temperature strength greater than alloy 903 and alloy 909 while maintaining an equivalent CTE.

The effect of $\mathrm{Cr}$ on mechanical properities and thermal expansion was studied by evaluating heats $7-1$ and 8 in Table 1 . Heat 7 has higher $\mathrm{Cr}$ and a higher $\mathrm{Co} /(\mathrm{CO}+\mathrm{Ni})$ ratio than heat 8 . Both have $\mathrm{Si}$ levels which are less than alloy A because of the expected improvement in SAGBO behavior from the additon of $\mathrm{Cr}$ (7). Both have the same amount of $\mathrm{Al}, \mathrm{Ti}$ and $\mathrm{Nb}$, and should precipitate 
Table 6 Effect of $\mathrm{Cr}$ and $\mathrm{Co} / \mathrm{Ni}$ ratio on hardness, Hv, stress-rupture properties and coefficient of thermal expansion"

\begin{tabular}{|c|c|c|c|c|c|c|c|c|c|c|}
\hline Heat & $\mathrm{Si}$ & $\mathrm{Cr}$ & $\mathrm{Co} /$ & Hardness & Stress & (MPa) & Life & Elong. & R.A. & CTE: $30-4007$ \\
\hline & & & $\left(\mathrm{Ni}+\mathrm{Co}_{0}\right)$ & (Hv) & initial & fina! & $(\mathrm{h})$ & $(\mathbf{y})$ & (\$) & $\times 105 / \tau$ \\
\hline $7-1$ (a)loy B) & 0.31 & 2.03 & 0.43 & 352 & 784 & 1078 & 263.5 & 13.9 & 29.3 & 7.92 \\
\hline 8 & 0.31 & 1.51 & 0.35 & 367 & 784 & 784 & 151.3 & notch & & 7.72 \\
\hline
\end{tabular}

a: Specimens were aged by overaging process

b: After 200h, stress was increased by $49 \mathrm{MPa}$ every 8 to $16 \mathrm{~h}$

the gamma prime phase. Both were overaged to observe the stability of the gamma prime precipitates. Mechanical properties and thermal expansion were evaluated.

\section{Results and Discussion}

Table 6 shows Vickers hardnesses, rupture properties and coefficients of thermal expansion for heats 7-1 and 8 . These alloys had almost the same level of hardness and thermal expansion. The CTE were nearly the same as alloy 903 and alloy 909 in Table 2, in spite of the $\mathrm{Cr}$ addition. Heat 7-1 had good rupture strength and ductility. Heat 8 failed in the notch at a lower net section stress than heat 7-1. This result is due to the decrease in Laves phase and accompanying larger grain size for heat 8 , as shown in Fig. 3. This figure also shows that the gamma prime precipitation hardening phase in these alloys is stable like alloy A in Fig. 2.

As a result of these experiments, it was found that heat 7 was an alloy with good high temperature strength and ductility, and a CTE similar to alloy 903 and alloy 909 . Heat 7 was designated alloy $B$, and additional evaluation tests were conducted, as discussed in the next section.

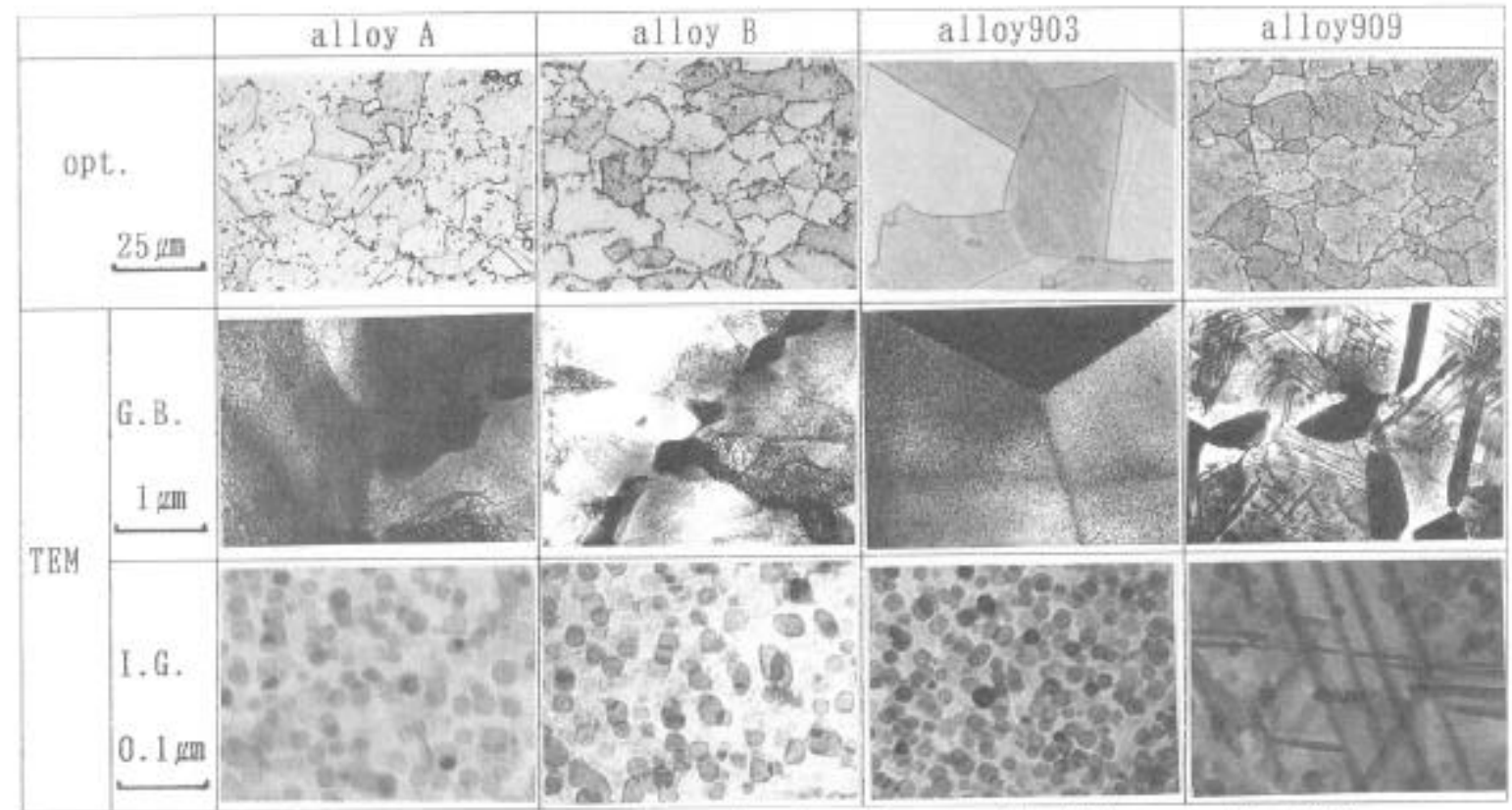

Fig. 4 Hicrostructures of developed alloys, alloy903 and alloy909 


\section{Expanded Mechanical Properties Evaluation of Alloys A and B}

In order to characterize alloys $A$ and $B$, a major test program was conducted, which included alloy 903 and alloy 909. The program evaluated microstructures via TEM; thermal expansion up to $800 \mathrm{C}$; tensile strength at room temperature, $500 \mathrm{C}$ and $650 \mathrm{C}$; creep rupture strength at $649 \mathrm{C}$ under constant stress; and stress-free oxidation at $800 \mathrm{C}$. Chemistries for alloys $A, B, 903$ and 909 are given in Table 1 , and are designated as heats $6-2,7-2,9$ and 10 , respectively. All of the specimens were given a standard aging heat treatment.

\section{Microstructure}

$\mathrm{Fig} .4$ s how $\mathrm{s}$ the microstructures of alloys $A$, B, 903 and 909. A11 alloys except alloy 903 have a fine grain size attributed to the pinning of grain boundaries by Laves phase. Spherical or cubic intergranular precipitates approximately ten nanometers in diameter are gamma prime pricipitates. Alloys A, B, and 903 have significant amounts of gamma prime. Alloy 909 has less gamma prime and a platelet precipitate. This platelet phase is supposed to be the $\varepsilon^{\prime \prime}$ phase, a $(\mathrm{Ni}, \mathrm{Co}, \mathrm{Fe}) 3(\mathrm{Nb}, \mathrm{Ti})$ transition phase (4), which is not effective for increasing tensile strength (6). It is believed that the lack of aluminum and excess amount of niobium caused the reduction in the amount of gamma prime precipitates and the precipitation of the $\varepsilon$ " phase.

\section{Thermal Expansion}

In Fig. 5, the CTE of alloy A is $25 \%$ lower than alloys 903 and 909 for the temperature range $30 \mathrm{C}$ to $400 \mathrm{C}$, while the CTE for alloy $B$ is almost the same as alloys 903 and 909 .

\section{Tensile Properties}

In Fig. 6, alloy $B$ shows the highest strength at $500 \mathrm{C}$ and $650 \mathrm{C}$ because of the $\mathrm{Cr}$ addition. Alloy $A$ has higher

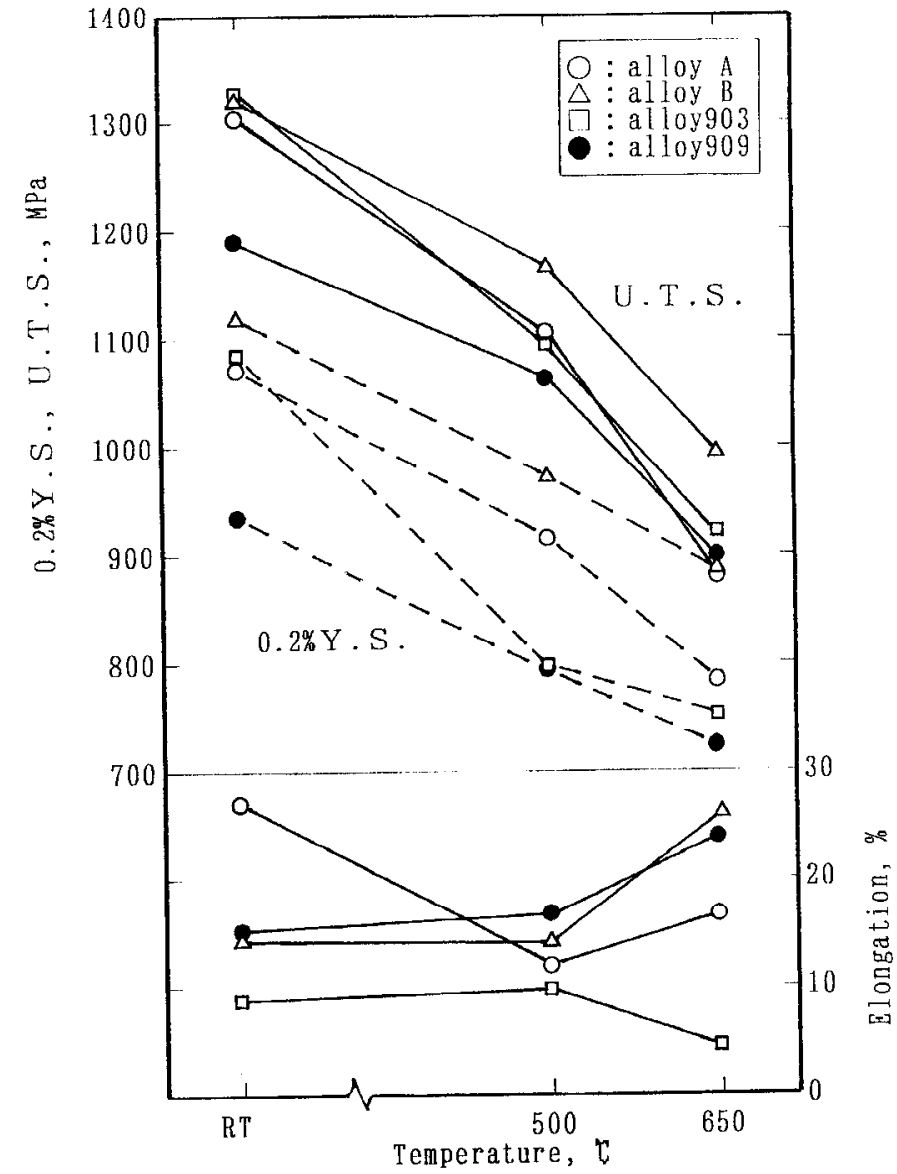

Fig. 6 Tensile properties of developed alloys, a $110 y 903$ and alloy909 


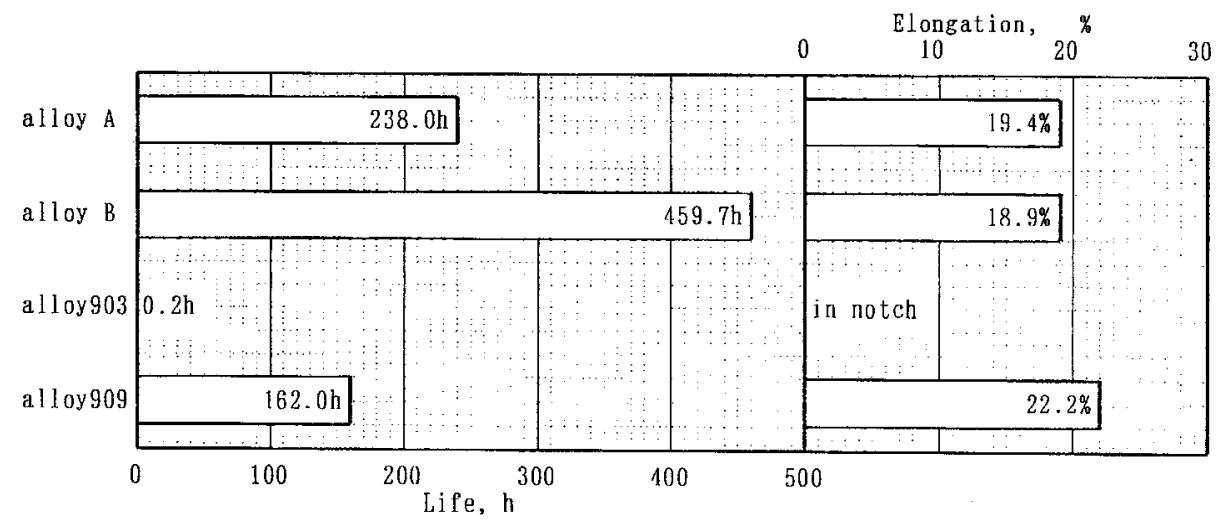

Fig. 7 Stress-rupture properties of developed alloys, alloy903 and alloygog Test condition: $649 \mathrm{~T}-510 \mathrm{MPa}$

$0.2 \%$ yield strength than alloys 903 and 909 at $500 C$ and $650 \mathrm{C}$. The tensile strength of alloy 909 is lower than that of Ref. 4, probably because excess amounts of $\varepsilon$ " phase were precipitated in this heat. Alloys $A$ and $B$ have adequate elongation values.

\section{Creep Rupture Properies}

Fig. 7 shows the creep rupture properties at $649 \mathrm{C} / 510 \mathrm{MPa}$. Alloy 903 is evidently inferior to the other alloys in rupture 1 ife and ductility, due to SAGBO embrittlement. The \% elongation values for alloys A, B and 909 are almost the same, but rupture lives

for alloys $A$ and $B$ are nearly one and a half times and three times longer, respectively, than alloy 909. Alloy $B$ had the longest rupture 1 ife, probably due to the $\mathrm{Cr}$ addition.

\section{Oxidation Resistance}

The poor oxidation resistance of low thermal expansion superalloys has been a problem area for this type of alloy. Fig. 8 shows the results of oxidation tests. Alloy $B$ with 2 wt\% $\mathrm{Cr}$ shows better oxidation resistance than alloy 903 and alloy 909, while alloy A shows almost the same level of oxidation resistance as alloy 903 and alloy 909.

\section{Summary}

Two alloys, $A$ and $B$, were developed which, when compared to alloys 903 and 909, either achieved a lower thermal expansion coefficeint while maintaining equivalent tensile strength, or increased tensile strength while maintaining an equivalent CTE. 
For alloy $\mathrm{A}$, an increase in the $\mathrm{Co} /(\mathrm{CO}+\mathrm{Ni})$ ratio produced a finer grain size (grain boundaries were pinned by Laves phase) and lower thermal expansion coefficient. The addition of aluminum did not affect rupture ductility but improved the stability of the gamma prime phase. The combination of a high $\mathrm{Co} /(\mathrm{Co}+\mathrm{Ni})$ ratio and a stable gamma prime phase produced a lower thermal expansion alloy compared to alloy 903 and alloy 909, while maintaining good rupture ductility. The composition is $0.45 \mathrm{Si}-29 \mathrm{Ni}-19.5 \mathrm{Co}-0.55 \mathrm{Al}-1.25 \mathrm{Ti}$ $4 \mathrm{Nb}-\mathrm{bal} \mathrm{Fe}$, by weight percent.

For alloy $\mathrm{B}, \mathrm{a} 2 \mathrm{wt} \% \mathrm{Cr}$ addition and slight chemistry modification of alloy A produced an alloy with improved high temperature tensile strength, ruptrue strength, and oxidation resistance, while maintaining almost the same level of thermal expansion as alloy 903 and alloy 909. The composition of this alloy is $0.3 \mathrm{Si}-29.5 \mathrm{Ni}-22.5 \mathrm{Co}-2 \mathrm{Cr}-0.55 \mathrm{Al}-1.25 \mathrm{Ti}-4 \mathrm{Nb}-\mathrm{bal} \mathrm{Fe}$, by weight percent.

\section{References}

1. D.R.Muzyka, C.R.Whitney and D.K.Schosser, "Physical Metallurgy and Properties of a New Controlled Expansion Superalloy," Journal of Metals, 27 (1975), 11-15.

2. R.H.Bricknell and D.A.Woodford, "Grain Boundary Embrittlement of Iron-Base Superalloy IN903A," Metall. Trans., 12A (1981), 1673-1679.

3. D.E.Smith and J.S.Smith, "A Silicon-Containing, Low-Expansion Alloy with Improved Properties," Superalloys 1984 (Conference Proceedings), TMS-AIME, (1984), 591-600.

4. K.A.Heck, D.F.Smith, J.S.Smith, D.A.Wells and M.A.Holderby, "The Physical Metallurgy of a Silicon-Containing Low Expansion Superalloy," Superalloys 1988 (Conference Proceedings), TMS-AIME, (1988), 151-160.

5. K.A.Heck, "The Effects of Silicon and Processing on the Structure and Properties of Incoloy Alloy 909," Physical Metall. of Controlled Expansion Invar-Type Alloys, TMS, (1990), 273-282.

6. E.A.Wanner, D.A.Deantonio, D.F.Smith and J.S.Smith, "The Current Status of Controlled Thermal Expansion Superalloys," Journal of Metals, 43(3) (1991), 38-43.

7. D.F.Smith, E.F.Clatworthy, D.G.Tipton and W.L.Mankins, "Improving the Notch-Rupture Strength of Low-Expansion Superalloys," Superalloys 1980 (Conference Proceedings), TMS-AIME, (1980) 521-530. 